\title{
Von der Natur der Politik und ihren Formen. Kleine Schriften
}

Tilo Schabert

Berlin 2020: Duncker \& Humblot, 450 S.

Mario Wintersteiger

FB Politikwissenschaft und Soziologie, Universität Salzburg

E-Mail: mario.wintersteiger@sbg.ac.at
In der Literatur zur Genese unseres Faches ist gelegentlich von einer „Münchner Schule“ der Politikwissenschaft die Rede; man darf sich diese jedoch nicht als einen einheitlichen, institutionalisierten Kreis vorstellen, vielmehr zeichnet sie sich durch ihre philosophische Grundorientierung an den großen Klassikern sowie durch ihre Offenheit für interkulturelle Fragen aus (vgl. dazu Göhler 1982, 36-37). Von dieser - inzwischen in unserer Disziplin leider rarer gewordenen - anthropologischen Breite und historischen Tiefe weiß auch Tilo Schabert $(2020,6)$ zu berichten und seine jüngst erschienene, von Frank-Lothar Kroll herausgegebene Sammlung kleiner Schriften legt selbst Zeugnis von diesem pluralistischen Wissenschaftsverständnis ab.

Der besprochene Band versammelt knapp drei Dutzend Texte aus mehreren Jahrzehnten, wobei viele davon in überarbeiteter Fassung und einige erstmals in deutscher Übersetzung vorgelegt werden. Somit wird zusammengetragen, was bisher auf vielerlei, auch entlegenere Orte verstreut war; abgerundet wird die Kollektion noch durch zwei Erstveröffentlichungen (vgl. 393-4Io). Die Formen der Präsentation - vom gehobenen Feuilleton über den festlichen Vortrag bis hin zum wissenschaftlichen Journalbeitrag - sind dabei ebenso vielfältig, wie es die Formen der untersuchten Politik sind. Um den Rahmen nicht zu sprengen, können wir hier daher nur pars pro toto - ein paar Kostproben für die Besprechung auswählen. Dabei scheint es sinnvoll, einige Leitmotive auszumachen, die die Textsammlung durchziehen: Eines davon betrifft die Grundstimmung des Bandes; ein zweites sein thematisches Profil; ein drittes bilden die darin besonders ausführlich behandelten Persönlichkeiten.
Auffallend ist zunächst einmal, dass hier in einer ausgesprochen frankophilen Atmosphäre über Politik nachgedacht wird - ein gutes Drittel der Beiträge ist Frankreich gewidmet und auch darüber hinaus begegnet man vielfach französischen Präsidenten (Charles de Gaulle, Valéry Giscard d'Estaing und insbesondere François Mitterrand) sowie frankophonen politischen Philosophen (wie Voltaire, Jean-Jacques Rousseau und Alexis de Tocqueville). Thematisch lässt sich ein Schwerpunkt auf die Erforschung von Regierungsstilen auf nationaler wie kommunaler Ebene ausmachen; hier fließen die umfangreichen Forschungen ein, die Schabert hinsichtlich des Élysée (vgl. 379-380) und der Stadtverwaltung von Boston, Massachusetts (vgl. I63) unternommen hat. Und schließlich kann man - schon an der Gliederung des Stoffes - gewissermaßen die Helden des Bandes in einem politikwissenschaftlich-politischen Zweigestirn ausmachen: Dieses wird gebildet von Eric Voegelin und François Mitterrand; der Erstere wird uns als „Geistesfürst“ (2O2) in seiner „Werkstatt“ (ebd.) vorgestellt, Letzterer erscheint vor uns als "klassischer Fürst" (345) im Élysée-Palast. Beiden widmen sich eigene, ausführliche Abschnitte (vgl. I9I-228 bzw. 343-4IO).

Die Ausführungen über die zwei ungleichen „Fürsten" gehören auch zu den interessantesten Kapiteln des Buches, findet man doch hier vielfach neue, ungewohnte Einblicke. Das liegt daran, das Schabert beide Protagonisten in persona kannte: Er promovierte bei Voegelin in München und begleitete ihn später als Research Fellow nach Kalifornien (vgl. 194). Mitterrands Regierungsweise hingegen konnte er im Rahmen eines mehrjährigen Forschungsprojektes im Élysée studieren (vgl. 379-380). Das Ergebnis sind Erfahrungs- und Gesprächsberichte 
(vgl. 4OI-4IO), aus denen wohl auch Fachleute so manches ihnen bislang noch unbekannte Detail mitnehmen können. Geprägt sind diese Darstellungen Schaberts von einer lebendigen, persönlich geprägten Erzählweise - mit all den Stärken und Schwächen, die eine solche Zugangsweise mit sich bringt. Angesichts der zwischenzeitlich erfolgten Versuche zu einer Entzauberung des Mythos Mitterrand ${ }^{\mathrm{I}}$ mögen die von einer gewissen Faszination getragenen Schilderungen heute vielleicht manchen etwas irritieren, doch erfährt man so viel Wissenswertes über die „öffentliche persona“ (389) des Präsidenten - und somit auch über die Kunst der Macht.

Was man zudem aus den kleinen Studien Schaberts mitnehmen kann, sind Einblicke in die großen Parallelen, welche sich hinsichtlich des Regierungsstils erfolgreicher Führungspersönlichkeiten vielfach zeigen: Dazu gehört das Ausmaß, in dem mit "personaler Macht“ (30) in informellen Räumen agiert wird (vgl. 30-3I), sich Freundeskreise als „zweite Regierung“ abseits der „eigentlichen Regierung" formieren (vgl. 263-270) und sich damit „klassische Strukturen“ (348) des Regierens herausbilden (vgl. 345-378).

Die weiteren Themen, denen sich Schabert widmet, können hier nur angedeutet werden: Sie reichen von Klassikern wie Platon (vgl. 63-80) bis hin zu den Körpern des Politischen (vgl. z. B. 97-IO3). Gewiss werden nicht all seine Deutungen immer auf ungeteilte Zustimmung stoßen - welch große Zankäpfel können schließlich Themen wie die adäquate Rousseau-Exegese (vgl. dazu I24-I47) oder die Beurteilung der Französischen Revolution (vgl. dazu 305-312) darstellen! Doch das schmälert nicht den Anregungswert der Ausführungen. Wer sich für die politische Ideengeschichte des Westens, die Fünfte Französische Republik oder klassisches Leadership interessiert und Denkanstöße dazu sucht, wird in diesem Band fündig werden.

\section{Literatur}

Göhler, Gerhard (1982), Die Freiburger und Münchner Schule als Scientific Community, Berlin: FU Berlin.

Ludwig, Arnold M. (2002), King of the Mountain. The Nature of Political Leadership, Lexington, Kentucky: The University Press of Kentucky.

I Die dabei diskutierten Enthüllungen sind freilich ihrerseits wieder geeignet aufzuzeigen, wie fähige politische Führungspersönlichkeiten an ihrem eigenen Mythos mitweben (vgl. dazu Ludwig 2002, 59-60, II4). 